\title{
Representasi Identitas Androgini di Media Sosial
}

\author{
Nadya Fhebrianty, Roswita Oktavianti \\ nadyafhebr@gmail.com,roswitao@fikom.untar.ac.id \\ Fakultas Ilmu Komunikasi Universitas Tarumanagara
}

\begin{abstract}
The androgyny concept in public's is still got a lot of misunderstanding. Androgyny has homosexual stereotypes such as Lesbi, Gay, Bisexual and Transgender (LGBT). Though the initial concept of androgyny is the concept of gender equality between masculinity and femininity. From the various views that occur in the community, it raises the pros and cons of the concept of androgyny. But now many people with androgynous identities are able to visualize themselves on social media. This research was conducted to determine the process of androgyny representation on Instagram social media. The approach used in this study is qualitative descriptive and uses phenomenological research methods. The subjects of this study were three androgynous informants. While the object of this research is Instagram social media. Data in this study collected by conducting interviews, observation, and documentation. The conclusion of this study is that androginy represents itself on social media through three representations. First, mental representations where androgyny is indifferent to negative interactions on social media, then the representation of language where androgyny visualizes itself with the use of ordinary language or by using certain symbols, and finally, social representation in the presence of social support from the environment, androgyny dared to decide to jump into social media.
\end{abstract}

Keywords: Androgyny, Representation, Social Media

\begin{abstract}
Abstrak
Di dalam masyarakat Indonesia, masih banyak terjadi kesalahpahaman mengenai konsep androgini. Androgini memiliki stereotipe homoseksual seperti Lesbi, Gay, Biseks dan Transgender (LGBT). Padahal konsep awal androgini adalah konsep kesetaraan gender antara femininitas dan maskulinitas. Berbagai pandangan pro dan kontra muncul di tengah masyarakat. Namun, saat ini banyak orang yang beridentitas androgini berani memvisualisasikan dirinya di media sosial terutama Instagram. Penelitian ini dilakukan untuk mengetahui proses representasi androgini di media sosial Instagram. Penelitian ini menggunakan pendekatan kualitatif deskriptif, dan menggunakan metode penelitian fenomenologi. Subjek dari penelitian ini adalah tiga informan androgini. Sedangkan objek dari penelitian ini adalah perilaku androgini dalam merepresentasikan diri di media sosial Instagram. Data dikumpulkan dengan melakukan observasi, wawancara dan dokumentasi. Kesimpulan dari penelitian ini adalah androgini merepresentasikan diri di media sosial melalui tiga representasi. Pertama, representasi mental, di mana androgini bersikap acuh terhadap interaksi negatif di media sosial. Selanjutnya, representasi bahasa, di mana androgini memvisualisasikan dirinya dengan penggunaan bahasa yang biasa atau dengan menggunakan simbol-simbol tertentu. Terakhir yaitu representasi sosial, dengan adanya faktor dukungan sosial dari lingkungan sekitar, androgini berani memutuskan untuk terjun ke media sosial.
\end{abstract}

Kata Kunci: Androgini, Representasi, Media Sosial 


\section{Pendahuluan}

Keberadaan laki-laki dan perempuan merupakan dua kondisi yang sering dibedakan antara jenis kelamin (seks) dan pembagian peran (gender). Istilah ini berasal dari Bahasa Latin, genus, yang berarti macam, jenis atau kelas. Istilah gender untuk menggambarkan makna menjadi seorang laki-laki atau perempuan terlepas dari perbedaan perbedaan biologis (Sharyn, 2010: 26). Androgini merupakan istilah yang berasal dari Bahasa Yunani, Andros, yang memiliki arti laki-laki, dan gyne, yang memiliki arti perempuan. Androgini merupakah suatu istilah di dalam identitas gender di mana seseorang tidak termasuk dengan jelas ke dalam peran feminin dan maskulin seperti yang berlaku di masyarakat.

Menurut Block, androgini adalah tingkat yang cukup tinggi dari kutub peran gender. Hal ini menyatakan bahwa seorang individu androgini dapat memiliki skor yang sama-sama tinggi dalam dua karakteristik. Setiap manusia dengan jenis kelamin laki-laki atau perempuan memiliki kedua unsur feminin dan maskulin. Namun, yang membedakannya adalah kadar yang dimiliki oleh individu tersebut. Individu androgini bisa memiliki ciri feminin dan maskulin yang sama-sama tinggi (Agustang, 2015).

Menurut Sandra Bem, psikolog feminisme Amerika, seseorang yang beridentitas androgini mempunyai gaya dan mental yang lebih fleksibel apabila dibandingkan dengan seseorang yang beridentitas feminin maupun maskulin. Androgini dimaknai sebagai gabungan di mana keadaan psikologis dari prinsip femininitas dan maskulinitas. Bem menyatakan bahwa psikologis androgini memungkinkan seseorang mampu memiliki dua peran gender yang kuat yaitu feminin dan maskulin yang dapat muncul secara bersamaan (Hargreaves, 2005: 28).

Menurut Hartley (2010: 265), representasi adalah penggunaan bahasa untuk mengutarakan sesuatu yang memiliki makna, mempresentasikan kepada orang lain. Representasi dapat berwujud kata, sekuen, cerita, gambar dan sebagainya yang menjadi suatu lambang yang mewakili ide, emosi, fakta, gagasan dan sebagainya.

Sedangkan menurut Stuart Hall, terdapat dua proses representasi. Pertama representasi mental, yaitu gagasan tentang sesuatu yang terdapat di kepala masingmasing atau peta konseptual. Kedua, representasi bahasa, memiliki peran penting di dalam proses konstruksi makna. Konsep abstrak yang terdapat di dalam kepala harus diterjemahkan dalam bahasa yang lazim, supaya dapat menghubungkan konsep dan ide tentang sesuatu dengan tanda dari simbol-simbol tertentu. Media sebagai suatu teks banyak menebarkan bentuk-bentuk representasi pada isinya. Representasi dalam media menunjuk kepada bagaimana suatu kelompok atau seseorang, pendapat atau gagasan tertentu ditampilkan dalam pemberitaan (Wibowo, 2010:122).

Sementara itu, menurut Moscovici, representasi sosial merupakan suatu gagasan fungsional yang membuat suatu kelompok atau individu memberikan nilai dan arti terhadap perbuatan yang dilakukannya untuk memahami suatu realita kehidupan yang sesuai referensi yang dimiliki dan untuk beradaptasi terhadap realitas tersebut. Representasi sosial ini merupakan cara untuk berpikir rasional melalui hubungan sosial dengan menggunakan logika dan gayanya sendiri, yang kemudian didistribusikan kepada kelompok yang sama melalui komunikasi yang sehari-hari (Deaux dan Philogene, 2001: 83).

Representasi sosial memiliki beberapa fungsi, antara lain: (1) Sebagai peraturan bagi seseorang untuk memahami dan menyesuaikan diri pada lingkungan fisik atau lingkungan sosialnya; (2) Representasi sosial juga dapat memungkinkan 
untuk terjadi aktivitas komunikasi antar anggota komunitas dengan sandi untuk aktivitas pertukaran sosial mereka, dan sebagai kode untuk menamai serta mengklarifikasikan dengan jelas berbagai macam aspek pada lingkungan (Deaux dan Philogene, 2001: 112); (3) berfungsi untuk menyelaraskan (coordinating) aktivitas kelompok atau memudahkan kerjasama antar anggotanya; (4) Rational Argumentation; (5) Symbolic Copying; (6) Environmental Compensation (Moscovici, dalam Andriana, 2009: 30).

Media sosial adalah sebuah media online yang mana para penggunanya dapat ikut berpartisipasi, membagi dan menciptakan isi di jejaring sosial, forum, wiki dan dunia virtual (Hikmat, 2018: 40). Adapun fungsi media sosial menurut Kietzman (Liliweri, 2015: 292-293), yaitu: (1) Identifity, (2) Sharing, (3) Conversation, (4) Presence, (5) Groups, (6) Relationships. Menurut Lometti, Reeves, dan Bybee penggunaan media oleh seseorang dapat dilihat dari tiga aspek, yaitu: (1) Jumlah waktu, hal ini berkaitan dengan intensitas, frekuensi dan durasi yang digunakan dalam mengakses situs; (2) Isi media, yaitu memilih media dan cara yang tepat agar pesan yang akan disampaikan dapat dikomunikasi dengan baik; (3) Hubungan media dengan seseorang dalam penelitian ini adalah keterkaitan pengguna dengan media sosial (Thea, 2016: 22).

Instagram makin populer sebagai aplikasi yang digunakan untuk berbagi foto mengakibatkan banyaknya pengguna media sosial yang terjun ke ranah bisnis seperti akun sosial bisnis yang turut mempromosikan produk-produknya lewat Instagram (Nisrina, 2015: 137)

Menurut Suprapto (2011: 17), komunikasi antarpersonal (interpersonal communication) adalah proses penyampaian ide, informasi dan sikap dari seseorang kepada orang lain. Definisi lain dari komunikasi massa yaitu, merupakan proses di mana pesan tersebut dicari, digunakan dan dikonsumsi oleh audiens (Bungin, 2013: 262). Kemudian definisi komunikasi massa menurut Gebner adalah produksi dan distribusi yang berbasis teknologi dan institusional dari aliran pesan yang terus menerus dibagikan secara luas dalam masyarakat industri.

Berdasarkan latar belakang di atas, penulis tertarik untuk melakukan penelitian yang berjudul "Representasi Identitas Androgini di Media Sosial"

\section{Metode Penelitian}

Penelitian ini menggunakan metode penelitian kualitatif. Menurut Sugiyono (2013: 2), metode penelitian ialah cara ilmiah untuk mendapatkan suatu data dengan kegunaan dan tujuan tertentu. Metode penelitian kualitatif sering disebut metode penelitian naturalistic karena penelitiannya dilakukan pada kondisi yang alamiah (natural setting).

Dalam penelitian ini, penulis menggunakan jenis penelitian kualitatif deskriptif, bertujuan untuk memberikan gambaran dan penjelasan yang mandalam mengenai objek. Sumber data diambil secara purposive dan snowball. Metode yang digunakan dalam penelitian ini adalah metode fenomenologi. Fenomenologi lebih memfokuskan pada konsep atau fenomena tertentu dan bentuk dari studinya adalah untuk melihat dan memahami arti dari suatu pengalaman individual yang berkaitan dengan fenomena tertentu (Herdiansyah, 2010: 66-68).

Pada penelitian ini, subjek yang digunakan oleh peneliti adalah pelaku androgini. Dengan narasumber bernama Michael Kalalo, Bambang Prakoso, dan 
Maria Deandra. Sedangkan objek penelitian ini yaitu perilaku menggunakan media sosial.

Data yang baik adalah data yang benar dipercayai kebenarannya (reliable), mencakup ruang yang luas dan tepat waktu serta memberikan gambaran yang jelas tentang suatu masalah secara sistematis, menyeluruh dan komprehensif (Ruslan, 2010:27). Data pada penelitian ini dikumpulkan penulis dengan melakukan: (1) Observasi non-participant, penulis melakukan observasi kepada pelaku androgini di media sosial Instagram, untuk mendapatkan data yang lengkap dan tajam; (2) Wawancara untuk mengetahui data yang mendalam dari narasumber; (3) Dokumentasi berupa catatan harian yang ditulis sendiri oleh peneliti, hasil wawancara, foto-foto dan agenda.

\section{Hasil Penelitian}

\section{a. Representasi Mental}

Menurut Stuart Hall ada dua proses representasi. Pertama, representasi mental, dan, kedua, representasi bahasa. Representasi mental yaitu konsep tentang sesuatu yang terdapat di kepala masing-masing atau peta konseptual. Sementara, representasi mental merupakan sesuatu yang terbilang abstrak (Wibowo, 2010:122).

Berdasarkan pemahaman di atas, dalam proses representasi mental seorang androgini terbentuk karena adanya pengalaman, pemikiran yang selalu positif masuk ke dalam tipe representasi mental non-konseptual karena adanya pengalaman mereka yang direspon dan mendapatkan perlakuan negatif.

Berdasarkan wawancara yang dilakukan bersama ketiga informan yang merupakan seorang androgini, pada awal terjun ke media sosial, banyak pengguna media sosial yang tidak menerima sehingga banyak yang memberi komentarkomentar negatif. Namun, mengacu pada representasi mental tipe representasi Hybrid, seiring berjalanya waktu informan mulai tidak mempedulikan komentarkomentar negatif tersebut dan menjadikan hal itu sebagai sesuatu yang positif untuk membangun diri menjadi lebih baik. Seperti pernyataan oleh informan 3, Maria Deandra, yang tidak pernah takut dengan komentar negatif dari pengguna media sosial karena informan telah merasa menjadi dirinya sendiri.

"Nggak pernah takut orang... kalau soal cara pakaian yang lebih maskulin gua nggak pernah takut sih. Kayak bodo amat aja. Ngerasa bebas. Karena emang gue begini" - (Informan 3, Maria Deandra).

\section{b. Representasi Bahasa}

Representasi bahasa berperan penting dalam proses konstruksi makna. Konsep abstrak yang ada dalam kepala harus diterjemahkan dalam bahasa yang lazim, agar dapat menghubungkan ide dan konsep tentang sesuatu dengan tanda dari simbolsimbol tertentu. Media sebagai sarana representasi dalam bentuk teks. Representasi dalam media menunjuk pada bagaimana seseorang atau suatu kelompok, gagasan atau pendapat tertentu ditampilkan dalam pemberitaan (Wibowo, 2010: 122).

Mengacu pada teori representasi bahasa, seorang androgini tidak memiliki perbedaan bahasa di dalam media sosial. Menurut pernyataan hasil wawancara penulis dengan informan 1, Michael Kalalo, selama sesama androgini merasa senang dengan gayanya sendiri, seorang androgini itu bebas dan tidak memiliki peraturan yang mengikat. 
"No... no... no, menurut aku ini aku kaya begini tuh gimana ya jadi ngerasa bebas aja gitu, itu nggak ada peraturan gitu sih selama lo kaum gue ngerasa happy mereka ngerasa dengan style mereka sendiri mereka bisa seneng bisa mengekspresikan diri ya go ahead nggak ada peraturan lo gini lo harus gitu ini selama nggak ngerugiin orang lain ya go ahead" - (Informan 1, Michael Kalalo).

Menurut pengamatan penulis, di media sosial Instagram, para informan merepresentasikan identitas androgininya melalui pernyataan di fitur live atau story di Instagram. Ketika para informan melakukan live di Instagram seringkali pengguna media sosial menanyakan identitas mereka. Para informan selalu mengaku dirinya tidak memiliki jenis kelamin tertentu atau non-binary atau genderless. Selain itu, para informan selalu menggunakan fashion feminin atau maskulin secara bergantian, tergantung dengan kondisi perasaan dari para informan.

Selain itu, menurut pengamatan penulis melalui media sosial informan, seorang androgini menunjukkan identitasnya melalui simbol-simbol tertentu yang menghubungkan dari konsep androgini tersebut. Keterangan foto (caption) yang menarik perhatian yang sangat berhubungan dengan foto yang diunggah.

\section{c. Representasi Sosial}

Menurut pernyataan informan 1, sebagai seorang risk taker, informan tidak peduli terhadap komentar apapun mengenai penampilannya yang feminin karena sejak kecil sang ibu selalu memberi kesempatan informan 1 untuk mencoba menggunakan pakaian-pakaian perempuan, make up. Informan 1 merasa nyaman berpakaian feminin karena sang ibu menerima, dan informan 1 merasa tidak merugikan siapapun. Dengan demikian informan 1 tidak mempedulikan dengan sterotipe yang ada.

Teori representasi sosial merupakan cara untuk berpikir yang rasional dan efektif melalui hubungan sosial dengan menggunakan logika dan gayanya tersendiri, yang kemudian diterjemahkan kepada suatu kelompok yang sama melalui komunikasi yang sehari-hari (Deaux dan Philogene, 2001: 83). Lingkungan pun menerima sehingga terbentuk pemikiran yang rasional serta praktis yang menjadikan terbentuknya gaya dan logikanya sendiri melalu hubungan sosial untuk didistribusikan kepada pengguna media sosial. Hal tersebut yang menjadikan seorang androgini berani untuk merepresentasikan identitas androgini di media sosialnya. Seperti pernyataan informan 2, Bambang Prakoso, berikut ini:

"Nah ini lagi pertanyaannya, aku nggak nyalahin kamu tapi cuma nyalahin orang-orang kaya gini aja. Kalau di Jerman aku gapapa, mereka open minded banget, kenapa sih kaya gabisa urus hidup masing-masing aja. Awalnya aku di judge banget sampe down. Cuma akhirnya aku ketemu temen-temen aku dan keluarga yang mendukung at lest b aja degan apa yang aku lakuin, aku merasa disupport dan akhirnya aku berani buka comment section. Awalnya susah deh apalagi di Indonesia, tapi itu ada bagusnya kaya memfilter orang yang bener-bener baik, aku jadi tau siapa aja yang bener-bener support aku. dan yaahh akhirnnya aku memutuskan untuk aku menjadi diri ku sendiri" - (Informan 2, Bambang Prakoso)

\section{d. Proses Representasi}

Mengacu pada proses representasi, anchoring adalah sebuah proses pengaitan atau pengenalan suatu objek tertentu dalam pikiran individu (Deaux dan Phologene, 2001: 135). Pada proses ini, informasi yang baru didapat diintegrasikan ke dalam sistem makna dan sistem pemikiran yang telah dimiliki oleh seseorang sebelumnya. 
Informan 2 menyatakan bahwa informan tidak pernah mencari cara untuk diterima oleh pengguna media sosial, informan comeout di media sosial karena kemauannya sendiri dan informan juga yang mengontrol media sosial. Jadi jika terdapat pengguna media sosial yang tidak menyukainya bukan alasan untuk informan 2 mengubah dirinya agar disukai oleh pengguna media sosial.

"Aku ga pernah cari cara untuk diterima nitizen. Aku punya sosmed kan atas kemauan ku dan aku juga yang kontrol sosmed aku, jadi aku mempost apapun yang aku suka. Jadi kalau mereka gak suka, itu bukan alasan aku buat berubah atau buat ga melakukan apa yang aku suka. Siapa tau dengan kamu menjadi diri kamu sendiri di sosial media kamu bisa ketemu dengan orang yang interestnya sama kaya kamu” -(Informan 2, Bambang Prakoso)

Proses representasi selanjutnya yaitu objectifications, adalah suatu proses untuk menerjemahkan gagasan yang abstrak dari suatu objek ke dalam gambaran tertentu yang lebih konkrit atau mengaitkan abstraksi tersebut dengan objek yang konkrit. Proses tersebut dipengaruhi oleh adanya kerangka sosial individu, contohnya nilai, norma, dan kode-kode yang merupakan bagian dari afek dari komunikasi atau proses kognitif serta penataan dan pemilihan representasi mental atas objek tersebut (Deaux dan Phologene, 2001: 135). Mengacu pada konsep di atas, seperti pernyataan Informan 3.

"Karena gua nyamannya kayak gini, dan gua juga kayak bodo amat. Terus itu kan balik lagi yang tadi gua bilang itu kan cuma social construct dan social constructnya itu dibangunnya dari kapan dan kalau buat dibawa ke sekarang kan bisa ngikutin jamannya dan kalau social construct sekarang tuh menurut gua udah nggak relevan bodo amat. Soalnya kek cara berpakaian cewek, kayak dulu kan cewek harus pake rok, terus kan makin kesini makin berubah. Cewek boleh pake celana segala macem, maksudnya kan social construct tuh harus bisa dinamis, ngikutin perubahan segala macem. Bukan kita yang harus ngikutin social construct mulu. Tapi itu kan sebenernya pilihan orang buat ngikutin ato engga, gua memilih untuk nggak ngikutin" - (Informan 3, Maria Deandra)

\section{e. Representasi sebagai sebuah konstruksi sosial}

Masyarakat sudah mengenal gender sejak manusia dilahirkan. Istilah gender berasal dari Bahasa Latin genus yang berarti jenis, macam, atau kelas. Istilah gender untuk menggambarkan makna menjadi seorang laki-laki atau perempuan terlepas dari perbedaan perbedaan biologis (Sharyn, 2010: 26)

Konsep gender ini membedakan tempat, waktu, tugas, peralatan, gerak-gerik, bentuk tuturan dan macam-macam persepsi yang dikaitkan pada perempuan atau laki-laki. Perbedaan gender diantara kedua jeniis kelamin akan menjadi lebih lebar ketika masyarakat pun mempertahankan perbedaan yang sifatnya bukan bawaan sejak lahir. Lebih dari itu, perbedaan itu justru dipertahankan secara kulturan. Perbedaan yang buka bawaan individual ini tidak lain adalah budaya patriarki.

"Konsep yang... konsep diluar... dua gender utama. She's female dan she's male kayak maksudnya kan andorgini kan kayak payung besar yang memayungi kayak.... Sub-sub gender lainnya kayak gender queer, fuid... segala macem lainnya. Terus konsep payung besarnya andorgini tuh gitu jadi gender jadi kayak gender tuh ga cuman item putih doang, tapi ada area yang bisa lo masukin tergantung nyamannya lo gimana, lo ga perlu harus kayak... lu lahirnya dengan jenis kelamin cewe lu harus berpakaian cewe segala macem dan gender lo harus she's female dan kebalikannya cowo juga gitu. Jadi lebih... kayak gimana ya.. keluar dari social 
construct yang udah bangun beberapa ratus tahun gitu sih. Simple nya kayak gitu”(Informan 3, Maria Deandra)

\section{Kesimpulan}

Proses representasi yang dilakukan oleh androgini di media sosial yaitu: Pertama, androgini memiliki persamaan konseptual representasi mental karena androgini tidak mempedulikan komentar negatif yang ada di media sosial. Menurut androgini, di media sosial lebih mudah menampilkan sisi androgini dibanding di dunia nyata, sehingga androgini merasa bebas dengan terjun ke media sosial. Kedua, dalam representasi bahasa, androgini memiliki kesamaan penggunaan bahasa. Penggunaan bahasa Indonesia maupun bahasa Inggris, serta penggunaan simbolsimbol tertentu untuk menunjang unggahannya. Namun, dalam kondisi emosional tertentu, androgini menggunakan lagu untuk diunggah di media sosial. Ketiga, dalam representasi sosial androgini memiliki faktor dukungan sosial dari lingkungan sekitar, orangtua, teman-teman. Androgini akhirnya berani memutuskan untuk terjun ke media sosial sehingga memiliki konsep tersendiri mengenai konstruksi sosial jenis kelamin dan gender.

\section{Ucapan Terima Kasih}

Ucapan terimakasih ditunjukan kepada Tuhan Yang Maha Esa, orang tua dan narasumber yaitu Michael Kalalo, Bambang Prakoso dan Maria Deandra Selain itu penulis juga ingin berterima kasih kepada teman-teman penulis yang telah banyak membantu penulis dalam menyelesaikan penelitian ini.

\section{Daftar Pustaka}

Agustang, Andi Tenri Pada, Muh. Said, dan Rusman Rasyid. 2015. "Perkembangan Peran Jender Dalam Prespektif Teori Androgini”. Jurnal. Dipresentasikan pada

Seminar Nasional Revolusi Mental dan Kemandirian Bangsa Melalui Pendidikan Ilmu-ilmu Sosial dalam Menghadapi MEA (28-29 November): 1-8 Bungin, Burhan (2010). Metode Penelitian Kualitatif. Jakarta: Rajawali Pers Bungin, Burhan. (2006). Teknik Praktis Riset Komunikasi. Jakarta: Kencana Davies, Sharyn Graham. (2018). Keberagaman Gender Di Indonesia. Jakarta: Yayasan Pustaka Obor Indonesia

Deaux, Kay dan Gina Philogene. (2001) Representations of the Social. Chicago: Blackwell

Hargreaves, Tracy. (2005). Androginy in Modern Literature. Basingstoke: Palgrave Macmillan

Hartley, J. (2010). Communication, Culture, and Media Studies, Konsep Kunci. Yogyakarta: Jalasutra

Herdiansyah, Haris (2010) Metodelogi Penelitian Kualitatif. Jakarta: Salemba Humanika

M. Nisrina. (2015). Bisnis Online, Manfaat Media Sosial Dalam Meraup Uang. Yogyakarta: Kobis

Rahmani, Thea (2016). Pengunaan Media Sosial sebagai Penguasaan Dasardasar Fotografi Ponsel (Studi Deskriptif Kualitatif pada akun Instagram @kofipon). Universitas Islam Negeri Sunan Kalijaga Yogyakarta 
Ruslan, Rosady. 2010. Metode Penelitian : Public Relations dan Komunikasi. Jakarta: PT. Raja Grafindo Persada

Sugiyono. (2013). Metodologi Penelitian Kuantitatif, Kualiatatif Dan $R \& D$. Bandung: Alfabeta

Sugiyono. (2017). Metodologi Penelitian Kuantitatif, Kualiatatif Dan R\&D. Bandung: Alfabeta

Suprapto, Tommy. (2011). Pengantar Ilmu Komunikasi dan Peran Manajemen dalam Komunikasi. Yogjakarta: Caps

Wibowo, Indiwan Seto Wahyu. (2011). Semiotika Komunikasi. Jakarta: Mitra Wacana Media 